\section{Protect against infectious diseases}

Don't let infectious diseases threaten the safety of patients or staff. Ensure your dental instruments are thoroughly cleaned and sterilised with reliable, proven solutions from W\&H.

The new Teon+ thermal washer disinfector offers dedicated programmes to ensure instruments are gently and effectively processed. With its user-friendly display and high-capacity chamber, the Teon+ can be combined with the new generation of W\&H sterilisers - including the Lara and Lisa type B vacuum steriliser - to further streamline your decontamination workflow.

Lisa has been innovatively designed with patented Eco Dry+ technology, which reduces the cycle time and optimises energy consumption for truly efficient sterilisation procedures.

Explore the decontamination range by visiting the W\&H website today.

To find out more visit www.wh.com/en_uk, call 01727874990 or email office.uk@wh.com.

\title{
Coming clean about sanitisers
}

During recent weeks it has become distressingly apparent that there is a high level of confusion amongst the general public about which sanitising products are effective against the coronavirus. Posts on social media, in particular, have often given incorrect advice and many are concerningly unaware that the products they are relying on to protect against infection are actually completely ineffectual against viruses.

The level of understanding is frankly woeful. A leading supplier of antiviral products to the healthcare sector explains what we need to know. According to Ross Walker of Clinical Health Technologies:

'Using any sanitiser is a good thing, but many are no more effective than a thorough hand wash with hot water and soap. If you have been using an antibacterial sanitiser to protect yourself against the virus I'm afraid you have been operating under a false sense of security as antibacterial sanitisers are only effective against bacteria, not viruses. Antimicrobial sanitisers however are effective against a wide spectrum of microbes including bacteria, mould, fungi and viruses.

'Another misconception is that only alcohol is effective against viruses which is completely incorrect. In fact, alcohol is one of the lesser effective chemistries and has to be used in concentrations of at least $70 \%$ in order to be effective.' Many alcohol sanitisers contain far lower concentrations than this.

By contrast the effectiveness of Clinisept+ against coronaviruses has been vigorously and independently tested and been proven to be highly effective in killing all enveloped viruses, including coronaviruses, in under 15 seconds. This is 240 times faster than the recognised test for virucidal efficiency (EN14476).

Clinisept + can be sprayed liberally directly onto the hands, face and surfaces to provide rapid protection against potential virus contamination.

The product uses a new chemistry which has not been available for the general public to purchase up until now, but has been used in hospitals, medical and dental clinics. The police and ambulance service have also now been given access to it.

Clinisept+ contains a proprietary ultra-pure hypochlorous solution which enables it to provide effective cleansing at a fraction of the strength of traditional cleansing chemistries. Clinisept+'s hypochlorous has a unique oxidising method of action which cleanses and provides antimicrobial protection but is also completely skin safe. It doesn't harm, irritate or sensitise the dermal layer. And because of the product's oxidising method of action, pathogens cannot become immune to it, meaning it is not subject to antimicrobial resistance.

The chemistry has undergone extensive independent testing proving not only that it is lethal to pathogens, but also the fact that it has a skin neutral $\mathrm{pH}$, is hypoallergenic and is even non-cytotoxic.

Clinical Health Technologies is doing its best to keep everyone safe and supplied with Clinisept+ but more needs to be done. The company has submitted evidence of Clinisept+'s effectiveness to the government for fast-track approval for use against all enveloped viruses, including coronavirus. This would allow Clinisept+ to be used more widely in a range of healthcare applications, particularly in the NHS, where its superior efficacy and safety would bring most benefit. In addition, Clinical Health Technologies has presented Clinisept+ for approval as a skin disinfectant to Public Health England and is also awaiting its response.

Plus, owing to the current shortage of plastic bottles in the UK and Europe, Clinical Health Technologies is also exerting pressure on the government to prioritise and ring fence production of bottles for the manufacture of Clinisept+ to allow them to significantly increase the current supply.

For more information visit www.cliniseptplus.com. 